\title{
Treatment for congenital toxoplasmosis: finding out what works
}

\author{
Ruth Gilbert \\ Centre for Paediatric Epidemiology and Biostatistics, UCL, Institute of Child Health, 30 Guilford Street, London WC1N 1EH, UK
}

Evidence for the effectiveness of prenatal or postnatal treatment for congenital toxoplasmosis will be critical to guide policy about prenatal and neonatal screening over the next 10 years, let alone the next 100. Randomised controlled trials are needed to address questions about treatment effectiveness, although cohort studies are also needed to provide information on prognosis, especially disability. Nowhere are such studies needed more than in South America where congenital toxoplasmosis is a major public health problem.

Key words: congenital toxoplasmosis - treatment - policy

Does treatment work? This is the central question that continues to trouble clinicians caring for mothers exposed to toxoplasmosis during pregnancy and their children. After more than a decade of international collaborative studies to address this question, we still do not have a clear answer. The imperative for the next 100 years, or even the next 10 years, is to answer this question.

The need for an answer is particularly urgent for prenatal treatment. At the moment, we do not know whether women and their babies are more likely to be helped than harmed when we offer prenatal screening. The clinical and ethical dilemmas are well known. Congenital toxoplasmosis only occurs when the mother acquires infection during pregnancy. The only way to reliably identify infected women is through serological screening, as few women have symptoms of infection and few infected fetuses show abnormal signs that might be detected by routine fetal ultrasound. This means that to find women who acquired toxoplasmic infection during pregnancy, we have to offer repeated screening tests to all pregnant women.

Ethically, we can only justify doing this if we can offer an intervention that will, on average, improve outcomes for the women who take up screening. The benefits need to be clear and measurable as the downsides are considerable (Gilbert and Peckham 2002). A positive test result turns a healthy pregnant woman into a woman who acquired an infection that she could have avoided, might blind her fetus and cause brain damage, and commits her to repeated testing, invasive fetal diagnosis and antibiotic treatment throughout pregnancy and her child to tests and treatment throughout infancy. She could consider the alternative intervention of pregnancy termination, but with rare exceptions, this is not generally acceptable as so many unaffected fetuses have to be terminated unnecessarily for every affected fetus (Berrebi et al. 1994, 2007, Bader et al. 1997, Thalib et al. 2005).

+ Corresponding author: r.gilbert@ich.ucl.ac.uk

Received 10 October 2008

Accepted 29 October 2008
The ethical imperative to demonstrate that benefits outweigh harms before implementing a screening programme has been echoed by numerous policy bodies (UK National Screening Committee 2003, Potter et al. 2008). These principles apply equally to neonatal screening for congenital toxoplasmosis, although there is even less evidence that postnatal treatment works than prenatal treatment. On the other hand, the harms and benefits are less finely balanced, as the harms associated with neonatal screening are fewer and less serious than for prenatal screening (Gilbert et al. 2006, Freeman et al. 2008, Potter et al. 2008). In this paper, I focus on the challenges to finding out whether treatment works, what we know already, and what researchers need to find out to make our practice more effective.

\section{Challenges}

Congenital toxoplasmosis poses several methodological challenges. In part, these explain why we still know so little about treatment effectiveness. Firstly, because infection during pregnancy can only be identified by screening, studies of treatment effectiveness can only be conducted in centres where prenatal screening is offered to all women. France, Austria and Italy provide universal screening, as do certain centres in Spain, Switzerland and Belgium (SYROCOT Study Group et al. 2007, Benard et al. 2008). Outside Europe, prenatal screening is often confined to the private sector (Neto et al. 2000, Segundo et al. 2004, Gilbert et al. 2008). Secondly, very large numbers of pregnant women need to be studied. This is partly because the incidence of infection during pregnancy is low, between 1-8 per 1,000 susceptible pregnancies, with the highest rates reported in France (Gilbert \& Peckham 2002). A further reason is the outcomes that are clinically important are rare. About one-third of infected women give birth to an infected fetus, but only $5 \%$ have serious neurological sequelae that would be apparent in the first two years of life (this is about $1.6 \%$ of infected pregnancies) (Gras et al. 2005, SYROCOT Study Group 2007). Thirdly, infected children need long term follow up to determine the impact of congenital toxoplasmosis on impairment or disability. By adolescence, about $30 \%$ of infected children have retinochoroiditis, but only $9 \%$ of these ( $2.7 \%$ of infected 
children and $0.9 \%$ of infected pregnancies) develop bilateral visual impairment severe enough to affect eligibility for a driving license (Wallon et al. 2004, Tan et al. 2007, Freeman et al. 2008). These are average figures for children born to treated and untreated mothers, but they illustrate that any reduction in risk associated with treatment is likely to be small.

A fourth challenge is the confounding effect of timing of maternal infection. Timing of infection is strongly linked to the risks of fetal infection and of brain lesions and neurological impairment. It is also linked to whether and when the woman is treated (Gilbert et al. 2003, Gras et al. 2005, Thiebaut et al. 2006, SYROCOT Study Group 2007). Given a monthly re-testing schedule for susceptible women, those infected early in the first trimester have a longer delay before treatment than women infected in the 2nd or 3rd trimesters, and women infected late in the 3rd trimester are less likely to be treated at all (Gilbert et al. 2003). A further problem is the difficulty of accurately measuring timing of infection (Thiebaut et al. 2006). Currently the best measure is detection of seroconversion. We do not know when seroconversion occurs exactly, only the interval between the last negative and first positive serological test. Increasingly, research studies are using special statistical methods to take into account the uncertainty of the timing of seroconversion (Gras et al. 2005, Thiebaut et al. 2006, SYROCOT Study Group 2007). Confounding is a particular problem for cohort studies which is minimised by randomised controlled trials.

The fifth challenge relates to the biology of the parasite. Toxoplasma gondii has a short 'therapeutic window' when treatment can act on tachyzoites. This 'window' is limited by the duration of maternal parasitaemia, which probably ceases with the development of the maternal serological response. Once parasites have entered the fetal circulation, the therapeutic window depends on how rapidly the fetal immune response drives the tachyzoite into the encysted, dormant bradyzoite form, which is impenetrable to antibiotics (Denkers et al. 1998). As fetal immunity matures, we would expect a shorter 'window' of tachyzoite replication, but the timing of maturation may differ between individuals (Jamieson et al. 2008). One implication of these findings is that early timing of treatment after maternal seroconversion is likely to be critical (Gras et al. 2005, SYROCOT Study Group 2007). Yet, as already outlined, measuring how soon treatment starts after maternal seroconversion is no easy task. A further implication of the need for early treatment is that prenatal treatment is likely to have a bigger effect on clinical manifestations in infected children than postnatal treatment.

The last challenge threatens the generalisability of findings across populations. Evidence is emerging that the clinical course of congenital toxoplasmosis differs in Europe and North America compared with parts of South America (Gomez-Marin et al. 2007, Gilbert et al. 2008). Ocular disease is five times more common in children with congenital toxoplasmosis identified by neonatal screening in Brazil than in children identified by prenatal or neonatal screening Europe. Moreover, lesions recur more frequently, are bigger and more likely to threaten vision (Gilbert et al. 2008). This is likely to be due to exposure to more virulent strains of $T$. gondii in Brazil. Type 1 and atypical strains appear to be associated with more severe ocular disease (Vallochi et al. 2005, Khan et al. 2006). compared with type II strains, which predominate in Europe and North America (Ajzenberg et al. 2004, de Moura et al. 2006, Dubey et al. 2006, 2007, Lehmann et al. 2006, Nowakowska et al. 2006). These findings suggest that treatment effectiveness in Europe and North America can not be extrapolated to settings where more virulent genotypes predominate. One reason is the absolute reduction in risk associated with treatment will be greater in settings where the baseline risk of adverse outcomes is higher. A second reason is that pharmacodynamics may differ. Evidence of strain differences in parasite replication, penetration of host tissues, and the interaction between parasite and host immunity, is starting to emerge (Saeij et al. 2006, 2007, Fux et al. 2007). So far, researchers have paid less attention to how these factors could affect the response to treatment and the need for early or continuing treatment.

\section{Prenatal treatment: what do we know already?}

So far, our knowledge about the effectiveness of prenatal treatment has been based entirely on cohort studies. The results are summarised for different treatment questions and outcomes in the Table. The most robust evidence comes from a systematic review and individual patient data meta-analysis of 20 European cohort studies $(1,438$ women $)$ in which universal screening for toxoplasmosis in pregnancy was performed (SYROCOT Study Group 2007). The analysis assessed the effect of timing and type of prenatal treatment on mother-to-child transmission of infection and clinical manifestations before age one year. Prenatal treatment consisted of spiramycin alone or pyrimethamine-sulphonamides and spiramycin followed by pyrimethamine-sulphonamides.

The systematic review found weak evidence that treatment started within three weeks of seroconversion reduced mother-to-child transmission compared with treatment started after eight or more weeks (Odds ratio 0.48, $95 \%$ CI $0.28-0.80 ; p=0.05$ ), but they could not distinguish whether this was a real benefit of treatment or a bias due to late detection and inclusion in the cohort of women at increased risk of fetal infection (SYROCOT Study Group 2007). Only one in five women were treated within three weeks of seroconversion, despite the fact that most (76\%) were identified in France, where a regimen of monthly retesting is mandated by law. Thus, even if early treatment is effective, it may be difficult to identify and treat women sufficiently quickly after seroconversion.

To date, no studies have found any evidence that early prenatal treatment reduces the risk of retinochoroiditis during infancy (SYROCOT Study Group 2007). Similarly, two large cohort studies that assessed the presence of retinochoroiditis in children up to school age found no evidence that prenatal treatment reduced the risk of lesions (Binquet et al. 2003, Freeman 2008). However, there is weak and inconsistent evidence that early prenatal treatment may have an impact on brain lesions in live-born children, though the findings of the systematic 
TABLE

Summary of evidence for different treatment comparison and outcomes

\begin{tabular}{|c|c|c|c|c|}
\hline & $\begin{array}{c}\text { Any treatment } \\
\text { vs } \\
\text { none }\end{array}$ & $\begin{array}{c}\text { Early } \\
\text { vs } \\
\text { delayed }\end{array}$ & $\begin{array}{c}\text { P\&S } \\
\text { VS } \\
\text { spiramycin alone }\end{array}$ & $\begin{array}{c}\text { Long } \\
\text { vs } \\
\text { short treatment }\end{array}$ \\
\hline \multicolumn{5}{|l|}{ Prenatal } \\
\hline Mother-child transmission & no eb & weak eb & no eb & ns \\
\hline Brain lesions & no eb & weak eb & no eb & ns \\
\hline Retinochoroiditis & no eb & no eb & no eb & ns \\
\hline Serious neuro impairment & in progress & ns & ns & ns \\
\hline Postnatal & & & ns & ns \\
\hline Retinochoroiditis after birth & no eb limited & no eb limited & ns & ns \\
\hline
\end{tabular}

no eb: no evidence of benefit. Cohort studies have been done, but show no evidence for differences in outcomes at the $5 \%$ level of significance; no eb limited: studies have addressed this comparison, but they had limited power to detect a difference; ns: no studies; weak eb: some studies have found a difference of borderline significance at the $5 \%$ level. Differences may be due to confounding or effect is not consistent across all studies that adjusted for gestational age at maternal seroconversion.

review were not significant at the 5\% level (Gras et al. 2005, SYROCOT Study Group 2007). Whether this is a true effect, or due to selection bias from exclusion of fetuses of treated women who were terminated after detection of intracranial lesions on fetal ultrasound is uncertain. Work is in progress to determine whether prenatal treatment reduces the risk of serious neurological sequelae in the $5 \%$ of congenitally infected infants with these findings (RE Gilbert, personal communication, on behalf of the European Multicentre Study of Congenital Toxoplasmosis, EMSCOT).

There is considerable debate about which type of prenatal treatment is best. Over the last 15 years, cohort studies have consistently found no evidence that treatment with a pyrimethamine-sulfonamide combination is more effective than spiramycin alone for reducing the risk of mother to child transmission of infection or clinical manifestations in the infected infant (Foulon et al. 1999, Gilbert et al. 2003, Gras et al. 2005, SYROCOT Study Group 2007, Freeman 2008). Randomised controlled trials are needed to resolve which type of treatment is best. This is because selection bias is likely to affect who receives which type of treatment. Secondly, results so far indicate that, at best, any effect of pyrimethaminesulphonamide combinations over spiramycin is likely to be small. Randomised controlled trials are much better for quantifying effects than cohort studies because they minimize error due to confounding.

Despite the lack of evidence for effectiveness, pyrimethamine-sulphonamide combinations are widely recommended, based on evidence that levels of spiramycin in fetal blood samples are about half those found in maternal serum and may be insufficient for treating fetal infection (Forestier et al. 1987, Remington 2006). This reasoning is questionable, given the difficulty in measuring blood levels of spiramycin and the extent of variation in blood levels between women (Gratzl et al. 1999). More importantly, pyrimethamine-sulphonamide combinations have two major disadvantages. Firstly, there is clear evidence from cohort studies that adverse drug effects are more common and more serious with pyrimethamine-sulphonamide combinations than with spiramycin during pregnancy (Daveluy et al. 2005). Secondly, if these treatments are equivalent, there may be no need to expose women to the risks of fetal loss and costs of prenatal diagnosis as there is no need to change treatment to a pyrimethamine-sulphonamide combination (Thalib et al. 2005).

Another important clinical question is whether it is necessary to continue treatment throughout pregnancy. There has been a long-standing belief that mother to child transmission may be delayed over weeks or months. Clinical studies comparing the timing of amniocentesis after maternal seroconversion provide no evidence to support this belief and the strong relationship between maternal seroconversion and congenital infection suggests that mother to child transmission occurs very early after infection (Thalib et al. 2005, SYROCOT Study Group 2007). So why continue treatment if prenatal diagnosis is negative? The reason often given is the poor sensitivity of prenatal diagnosis based on PCR. However, clinicians and the women themselves might want to reflect on the risks involved. For a woman who seroconverts at 12 weeks of gestation who has a negative PCR test (sensitivity around 33\%), her risk of mother to child transmission is at the most, $3 \%$ (Thalib et al. 2005). If treatment is effective, the risk will be even lower, as she would have been treated prior to prenatal diagnosis.

\section{Prenatal treatment: what are the research priorities?}

The systematic review concluded that only a large randomised controlled clinical trial that compared prenatal treatment with no treatment or placebo, could provide clinicians and patents with valid evidence of the potential benefit of prenatal treatment (SYROCOT Study Group 2007). Randomisation of individual women is the only way to minimise problems of selection bias related to disease severity and confounding due to timing of maternal seroconversion. From a policy perspective, randomised controlled trials need to compare treatment 
with no treatment, or better still, with placebo. Only then can policy makers know whether the more than 100 million Euros spent each year on prenatal screening in France are cost effective (Gilbert \& Peckham 2002). Such trials need to be carefully designed given the ethical imperative for benefit once screening has identified a problem that the woman would not otherwise have known about. Trials that aim to minimise harms of treatment are also urgently needed. These may take the form of 'head to head' comparisons of different treatments (e.g.: pyrimethamine-sulphonamide vs spiramycin) or withdrawal trials [e.g.: treatment throughout pregnancy compared with short course treatment for women with a negative prenatal diagnosis (Table)]. Such trials would aim to establish whether outcomes (e.g.: transmission or clinical manifestations) are equivalent for the comparison groups. If they are, rational clinical practice would favour the least harmful option. These recommendations for progressing understanding of treatment effectiveness apply regardless of setting or parasite strain.

The systematic review stated very clearly that further evidence from cohort studies would be unlikely to change what we already know about treatment effectiveness (SYROCOT Study Group 2007). This is true. But cohort studies remain vital to determine prognosis, particularly the risk and severity of disability later in childhood. Nowhere are such prognostic studies needed more than in South America, where the disease is a major public health problem. Furthermore, such cohort studies should be multicentre, using the same protocol so that outcomes are comparable, and conducted in different regions depending on which strains predominate. Tried and tested follow up protocols are available for researchers from the Brasil-EMSCOT study (Gilbert et al. 2008). These would allow results to be compared with previous cohorts in Brazil and Europe. Even less attention has been given to researching the burden and clinical course of congenital toxoplasmosis in Africa, despite some evidence of severe disease, particularly in West Africa (Ronday et al. 1996, Gilbert et al. 1999).

\section{Postnatal treatment: what do we know already?}

Postnatal treatment is usually given to infected infants as prophylactic treatment to reduce the risk of retinochoroiditis developing after birth. The rationale for prophylaxis early in infancy is that cyst density diminishes with time after infection and cyst breakdown occurs more frequently with less mature immunity. Conversely, we could expect prophylaxis to be less effective as the child's own immune response matures. A further reason is that the alternative option, symptomatic treatment in response to ocular symptoms, only becomes feasible as children grow older and are able to express symptoms.

The effect of postnatal treatment has not been addressed by any concurrent comparative studies because once a baby is identified as infected, most clinicians have felt obliged to treat (Freeman et al. 2008). One exception was a Dutch cohort of 12 infected infants, half of whom were treated prenatally. Paediatricians could not be persuaded to treat postnatally, because infants had no or only mild signs, and because of the lack of evidence that benefits justified a burdensome and potentially harmful treatment regimen (Gilbert et al. 2001). A comparison of the Dutch cohort with other cohorts in which children were treated postnatally, or prenatally and postnatally, showed no significant difference in the risk of retinochoroiditis by three years of age (Gilbert et al. 2001). However, the power to detect an effect was limited. In the EMSCOT cohort, we found no evidence for an effect of early versus late postnatal treatment on newly occurring retinochoroiditis after an initial negative examination (Gilbert et al. 2001). However, the power to detect an effect was low. Differences reported between referred case series of children in the USA in the 1950s (untreated) and more recently (treated) are uninterpretable (McAuley et al. 1994). Postnatal treatment is only one of many explanations for the difference in outcomes, another being referral bias favouring less severely infected children in the more recent cohort. In summary, it is hard to deduce anything about the effectiveness of postnatal treatment from cohort studies todate. Randomised controlled trials are urgently needed to evaluate prophylactic treatment.

\section{Postnatal treatment: what are the research priorities?}

To design trials to evaluate postnatal treatment, we need to be clear about the underlying prognosis for new retinochoroidal lesions after birth and the likely magnitude of the treatment effect. We know from the lack of evidence for a significant effect of prenatal treatment on retinochoroidal lesions that any effect of postnatal treatment is likely to be small (Binquet et al. 2003, SYROCOT Study Group 2007, Freeman et al. 2008). To expect postnatal treatment to halve the risk of new lesions (relative risk of 0.5 ) would be extremely optimistic, and a $20 \%$ reduction might be more realistic (relative risk 0.8 ). Secondly, we know from European cohorts that $84 \%$ of infected children identified by screening and with no retinochoroiditis or other clinical manifestations detected at postnatal examinations before four months of age have a low risk $(8 \%$; $95 \%$ CI: $4-12 \%)$ of developing retinochoroiditis by four years of age (Freeman et al. 2008). Their risk of bilateral visual impairment will be much less than the $9 \%$ estimated for all children with retinochoroiditis as this group of children had no lesions at birth (Tan et al. 2007). These data are from treated children, but the risk for untreated children will not be much higher given the small expected treatment effect.

The implications are that for five out of six infected infants identified by European screening programmes, the harms of postnatal treatment for one year could readily outweigh any benefits. So what should clinicians and researchers do? Firstly, there is an ethical imperative to share this information with parents when making decisions about postnatal treatment and follow up. Secondly, clinicians should consider not treating and not following up these children. Evidence is needed of the effectiveness of repeated routine ophthalmic examinations throughout childhood for children with normal ophthalmoscopy after birth given their low risk of retinochoroiditis. Instead, clinicians could advise parents to bring the child for assessment should ocular signs or symptoms develop, and 
ensure that routine school vision screening is undertaken at 3-4 years old. In the Danish cohort, ophthalmologists could not be persuaded of the benefits of annual ophthalmoscopy examinations (E Petersen, personal communication), whereas in some centres examinations are repeated at six monthly intervals (Freeman et al. 2008). We previously reported that at 3-4 years, infected and uninfected children born to toxoplasma infected mothers had no detectable differences in a range of developmental outcomes, but parents of infected children were significantly more anxious (Freeman et al. 2005). Part of this anxiety may be attributable to concerns about vision loss in their child, a fear that is reinforced by repeated examinations. Thirdly, these alternative strategies should be evaluated in a randomised controlled trial, although the challenges to doing so are considerable. The trial would need to be very large, because the expected difference is small, and follow up would need to be for many years. A further problem is that lack of blinding of treatment allocation and the need for intermittent assessments in both trial arms over a long period would make contamination between trial arms quite likely. In other words, children allocated to treatment might well stop taking it, and those allocated to no treatment might be more ready to start treatment for any small peripheral lesion found on routine examination. A fourth option for neonatal screening centres is to stop screening. After starting the programme in 1992, the Danish National Screening Programme took the decision to stop screening in August 2007 because of the low burden of disease and lack of evidence that treatment is effective (E Petersen, personal communication). Neonatal screening programmes in Massachusetts and Ireland, both areas where the type II genotype of the parasite predominates, should similarly consider whether ongoing screening is justified (Gilbert \& Dezateux 2006).

The research priority for children with clinical signs after birth (16\% of infected children in European cohorts) is for treatment withdrawal or harm limitation trials. This would mean randomising infected children to 12 month or three months of treatment or to less toxic treatment regimens compared with the standard pyrimethamine-sulphonamide combination.

The need for trials of different treatment options is even more urgent for South America where the large majority of infected children identified by screening have clinical signs detected after birth. In addition, their risk of subsequent retinochoroiditis is very much higher than for children in Europe and the risk of visual impairment given a lesion is higher. The impact of visual impairment on quality of life and economic sustainability in adulthood is also likely to be worse in less developed settings. On the other hand, the potential harms of neutropenia due to treatment, and the burden of treatment and complying with follow up, may also be higher in less developed settings.

While Europe and North America argue the ethics and cost effectiveness of marginal benefits of screening programmes, evidence is emerging from high quality, population-based studies in South America that congenital toxoplasmosis is a major public health problem (Bahia-
Oliveira et al. 2001, Neto et al. 2004, Portela et al. 2004, Gomez-Marin et al. 2007, Lago et al. 2007, Andrade et al. 2008, Gilbert et al. 2008). Moreover, these clinician researchers are demonstrating that they can implement neonatal screening and follow up programmes to the high standards of quality that need to be reached before screening can be considered a feasible option.

The onus is now on the research community and research funders. In South America congenital toxoplasmosis is an important public health problem that prenatal or neonatal screening, or both, may help to ameliorate. Policy makers need to know whether treatment works and whether screening is cost effective. This requires coordinated, high quality, multicentre randomised controlled trials, linked to ongoing cohort studies of children identified by screening. Researchers in South America have shown that the skills and infrastructure are there to answer these questions in the next 10 years rather than the next 100 . What is needed is prioritisation from international funders and fruitful collaboration.

\section{ACKNOWLEDGEMENTS}

To my collaborators in the EMSCOT, EUROTOXO and SYROCOT studies, whose work I have drawn on extensively for this review. They include K Freeman, EG Lago, L BahiaOliveira, W Buffolano, HK Tan, M Stanford, M Wallon, E Petersen, P Thulliez, S Romand, F Peyron, D Remmer Schmidt, M Paul, A Prusa, M Hayde, A Pollak, M-H Bessières, J Franck, H Dumon, P Bastien, E Issert, C Chemla, N Ferret, P Marty, H Pelloux, B Evengard, G Malm, E Semprini, M Cortina-Borja, L Gras, L Thalib, R Thiébaut, S Leproust, G Chêne, R Salmi, A Bènard and R Salamon.

\section{REFERENCES}

Ajzenberg D, Banuls AL, Su C, Dumetre A, Demar M, Carme B, Darde ML 2004. Genetic diversity, clonality and sexuality in Toxoplasma gondii. Int J Parasitol 34: 1185-1196.

Andrade GM, Resende LM, Goulart EM, Siqueira AL, Vitor RW, Januario JN 2008. Hearing loss in congenital toxoplasmosis detected by newborn screening. Rev Bras Otorrinolaringol (Engl Ed) $74: 21-28$.

Bader TJ, Macones GA, Asch DA 1997. Prenatal screening for toxoplasmosis. Obstet Gynecol 90: 457-464.

Bahia-Oliveira LMG, Abreau AMW de, Azevedo-Silveira J, Orefice F 2001. Toxoplasmosis in Southeastern Brazil: an alarming situation of highly endemic acquired and congenital infection. Int $J$ Parasitol 32: 133-137.

Benard A, Petersen E, Salamon R, Chene G, Gilbert R, Salmi LR 2008. Survey of European programmes for the epidemiological surveillance of congenital toxoplasmosis. Euro Surveill 13: 15.

Berrebi A, Bardou M, Bessieres MH, Nowakowska D, Castagno R, Rolland M, Wallon M, Franck J, Bongain A, Monnier-Barbarino P, Assouline C, Cassaing S 2007. Outcome for children infected with congenital toxoplasmosis in the first trimester and with normal ultrasound findings: a study of 36 cases. Eur J Obstet Gynecol Reprod Biol 135: 53-57.

Berrebi A, Kobuch WE, Bessieres MH, Bloom MC, Rolland M, Sarramon MF, Roques C, Fournie A 1994. Termination of pregnancy for maternal toxoplasmosis. Lancet 344: 36-39.

Binquet C, Wallon M, Quantin C, Kodjikian L, Garweg J, Fleury J, Peyron F, Abrahamowicz M 2003. Prognostic factors for the 
long-term development of ocular lesions in 327 children with congenital toxoplasmosis. Epidemiol Infect 131: 1157-1168.

Daveluy A, Haramburu F, Bricout H, Costanzo MC, Fourrier A, Tan HK, Gilbert RE, Kieffer F, Thiebaut R 2005. Review of data related to side effects of drugs used in congenital toxoplasmosis, Bordeaux, Panel 2. Available from: http://eurotoxo.isped.u-bordeaux2. $\mathrm{fr} / \mathrm{www}$ public/us-eurotoxo-publicaccess-frame-2.htm.

de Moura L, Bahia-Oliveira LM, Wada MY, Jones JL, Tuboi SH, Carmo EH, Ramalho WM, Camargo NJ, Trevisan R, Graca RM, da Silva AJ, Moura I, Dubey JP, Garrett DO 2006. Waterborne toxoplasmosis, Brazil, from field to gene. Emerg Infect Dis 12: 326-329.

Denkers EY, Gazzinelli RT 1998. Regulation and function of T-cellmediated immunity during Toxoplasma gondii infection. Clin Microbiol Rev 11: 569-588.

Dubey JP, Su C, Cortes JA, Sundar N, Gomez-Marin JE, Polo LJ, Zambrano L, Mora LE, Lora F, Jimenez J, Kwok OC, Shen SK, Zhang X, Nieto A, Thulliez P 2006. Prevalence of Toxoplasma gondii in cats from Colombia, South America, and genetic characterization of $T$. gondii isolates. Vet Parasitol 141: 42-47.

Dubey JP, Sundar N, Gennari SM, Minervino AH, Farias NA, Ruas JL, dos Santos TR, Cavalcante GT, Kwok OC, Su C 2007. Biologic and genetic comparison of Toxoplasma gondii isolates in free-range chickens from the northern Para state and the southern state of Rio Grande do Sul, Brazil, revealed highly diverse and distinct parasite populations. Vet Parasitol 143: 182-188.

Forestier F, Daffos F, Rainaut M, Desnottes JF, Gaschard JC 1987. Fetomaternal therapeutic follow-up of spiramycin during pregnancy. Arch Fr Pediatr 44: 539-544.

Foulon W, Villena I, Stray-Pedersen B, Decoster A, Lappalainen M, Pinon JM, Jenum PA, Hedman K, Naessens A 1999. Treatment of toxoplasmosis during pregnancy: a multicentre study of impact on fetal transmission and children's sequelae at age 1 year. $\mathrm{Am} J$ Obstet Gynecol 180: 410-415.

Freeman K, Salt A, Prusa A, Malm G, Ferret N, Buffolano W, Schmidt D, Tan HK, Gilbert RE 2005. Association between congenital toxoplasmosis and parent-reported developmental outcomes, concerns and impairments, in 3 year old children. Biomed Central Pediatrics 5: 23.

Freeman K, Tan HK, Prusa A, Petersen E, Buffolano W, Malm G, Cortina-Borja M, Gilbert R 2008. Predictors of retinochoroiditis in children with congenital toxoplasmosis: European, prospective cohort study. Pediatrics 121: e1215-e1222.

Fux B, Nawas J, Khan A, Gill D, Su C, Sibley LD 2007. Toxoplasma gondii strains lacking oral transmission are defective in stage differentiation. Infect Immun 62: 1761-1767.

Gilbert R, Dezateux C 2006. Newborn screening for congenital toxoplasmosis: feasible, but benefits are not established. Arch Dis Child 91: 629-631.

Gilbert R, Dunn D, Wallon M, Hayde M, Prusa A, Lebech M, Kortbeek T, Peyron F, Pollak A, Petersen E 2001. Ecological comparison of the risks of mother-to-child transmission and clinical manifestations of congenital toxoplasmosis according to prenatal treatment protocol. Epidemiol Infect 127: 113-120.

Gilbert R, Gras L 2003. Effect of timing and type of treatment on the risk of mother to child transmission of Toxoplasma gondii. BJOG 110: $112-120$

Gilbert RE, Dunn D, Lightman S, Murray PI, Pavesio C, Gormley P, Masters J, Parker SP, Stanford MR 1999. Incidence of symptomatic toxoplasma eye disease: aetiology and public health implications. Epidemiol Infect 123: 283-289.

Gilbert RE, Freeman K, Lago EG, Bahia-Oliveira LM, Tan HK, Wal- lon M, Buffolano W, Stanford MR, Petersen E 2008. Ocular sequelae of congenital toxoplasmosis in Brazil compared with Europe. PLoS Negl Trop Dis 2: e277.

Gilbert RE, Peckham CS 2002. Congenital toxoplasmosis in the United Kingdom: to screen or not to screen? J Med Screen 9: 135-141.

Gomez-Marin JE, Gonzalez MM, Montoya MT, Giraldo A, Castano JC 2007. A newborn screening programme for congenital toxoplasmosis in the setting of a country with less income. Arch Dis Child 92: 88.

Gras L, Wallon M, Pollak A, Cortina-Borja M, Evengard B, Hayde M, Petersen E, Gilbert RE, EMSCOT 2005. Association between prenatal treatment and clinical manifestations of congenital toxoplasmosis in infancy: a cohort study in 13 European centers. Acta Paediatrica Scandinavia 94: 1-12.

Gratzl R, Hayde M, Kohlhauser C, Hermon M, Burda G, Strobl W, Pollak A 1999. Follow-up of infants with congenital toxoplasmosis detected by polymerase chain reaction analysis of amniotic fluid. Eur J Clin Microbiol Infect Dis 17: 853-858.

Jamieson SE, de Roubaix LA, Cortina-Borja M, Tan HK, Mui EJ, Cordell HJ, Kirisits MJ, Miller EN, Peacock CS, Hargrave AC, Coyne JJ, Boyer K, Bessieres MH, Buffolano W, Ferret N, Franck J, Kieffer F, Meier P, Nowakowska DE, Paul M, Peyron F, Stray-Pedersen B, Prusa AR, Thulliez P, Wallon M, Petersen E, McLeod R, Gilbert RE, Blackwell JM 2008. Genetic and epigenetic factors at COL2A1 and ABCA4 influence clinical outcome in congenital toxoplasmosis. PLOS ONE 3: e2285.

Khan A, Jordan C, Muccioli C, Vallochi AL, Rizzo LV, Belfort R Jr, Vitor RW, Silveira C, Sibley LD 2006. Genetic divergence of Toxoplasma gondii strains associated with ocular toxoplasmosis, Brazil. Emerg Infect Dis 12: 942-949.

Lago EG, Neto EC, Melamed J, Rucks AP, Presotto C, Coelho JC, Parise C, Vargas PR, Goldbeck AS, Fiori RM 2007. Congenital toxoplasmosis: late pregnancy infections detected by neonatal screening and maternal serological testing at delivery. Paediatr Perinat Epidemiol 21: 525-531.

Lehmann T, Marcet PL, Graham DH, Dahl ER, Dubey JP 2006. Globalization and the population structure of Toxoplasma gondii. Proc Natl Acad Sci USA 103: 11423-11428.

McAuley J, Boyer KM, Patel D, Mets M, Swisher C, Roizen N, Wolters C, Stein L, Stein M, Schey W, Remington J, Meier P, Johnson D, Heydeman P, Holfels E, Withers S, Mack D, Brown C, Patton D, McLeod R 1994. Early and longitudinal evaluations of treated infants and children and untreated historical patients with congenital toxoplasmosis: the Chicago collaborative treatment trial. Clin Infect Dis 18: 38-72.

Neto EC, Anele E, Rubim R, Brites A, Schulte J, Becker D, Tuuminen $\mathrm{T} 2000$. High prevalence of congenital toxoplasmosis in Brazil estimated in a 3-year prospective neonatal screening study. Int $J$ Epidemiol 29: 941-947.

Neto EC, Rubin R, Schulte J, Giugliani R 2004. Newborn screening for congenital infectious diseases. Emerg Infect Dis 10: 1068-1073.

Nowakowska D, Colon I, Remington JS, Grigg M, Golab E, Wilczynski J, Sibley LD 2006. Genotyping of Toxoplasma gondii by multiplex PCR and peptide-based serological testing of samples from infants in Poland diagnosed with congenital toxoplasmosis. J Clin Microbiol 44: 1382-1389.

Portela RW, Bethony J, Costa MI, Gazzinelli A, Vitor RW, Hermeto FM, Correa-Oliveira R, Gazzinelli RT 2004. A multihousehold study reveals a positive correlation between age, severity of ocular toxoplasmosis and levels of glycoinositolphospholipid-specific immunoglobulin A. J Infect Dis 190: 175-183.

Potter BK, Avard D, Wilson BJ 2008. Newborn blood spot screen- 
ing in four countries: stakeholder involvement. J Public Health Policy 29: 121-142.

Remington JMRTPDG 2006. Toxoplasmosis. In Infectious disease of the fetus and newborn infant, JKJWCBC Remington(ed.), Elsevier Saunders, Philadelphia, p. 947-1092.

Ronday MJ, Stilma JS, Barbe RF, McElroy WJ, Luyendijk L, Kolk AH, Bakker M, Kijlstra A, Rothova A 1996. Aetiology of uveitis in Sierra Leone, West Africa. Br J Ophthalmol 80: 956-961.

Saeij JP, Boyle JP, Coller S, Taylor S, Sibley LD, Brooke-Powell ET, Ajioka JW, Boothroyd JC 2006. Polymorphic secreted kinases are key virulence factors in toxoplasmosis. Science 314: 1780-1783.

Saeij JP, Coller S, Boyle JP, Jerome ME, White MW, Boothroyd JC 2007. Toxoplasma co-opts host gene expression by injection of a polymorphic kinase homologue. Nature 445: 324-327.

Segundo GR, Silva DA, Mineo JR, Ferreira MS 2004. A comparative study of congenital toxoplasmosis between public and private hospitals from Uberlândia, MG, Brazil. Mem Inst Oswaldo Cruz 99: 13-17.

Tan HK, Schmidt D, Stanford M, Tear-Fahnehjelm K, Ferret N, Salt A, Gilbert R 2007. Risk of visual impairment in children with congenital toxoplasmic retinochoroiditis. Am J Ophthalmol 144: 648-653.
Thalib L, Gras L, Romand S, Prusa A, Bessieres MH, Petersen E, Gilbert RE 2005. Prediction of congenital toxoplasmosis by polymerase chain reaction analysis of amniotic fluid. BJOG 112: $567-574$.

The SYROCOT Study Group, Thiebaut R, Leproust S, Chene G, Gilbert RE 2007. Effectiveness of prenatal treatment for congenital toxoplasmosis: a meta-analysis of individual patients' data. Lancet 369: 115-122.

Thiebaut R, Leroy V, Alioum A, Binquet C, Poizat G, Salmi LR, Gras L, Salamon R, Gilbert R, Chene G 2006. Biases in observational studies of the effect of prenatal treatment for congenital toxoplasmosis. Eur J Obstet Gynecol Reprod Biol 124: 3-9.

UK National Screening Committee 2003. UK National Screening Committee criteria for appraising the viability, effectiveness and appropriateness of a screening programme. Available from: http://www.nsc.nhs.uk/uk_nsc/uk_nsc_ind.htm.

Vallochi AL, Muccioli C, Martins MC, Silveira C, Belfort R Jr, Rizzo LV 2005. The genotype of Toxoplasma gondii strains causing ocular toxoplasmosis in humans in Brazil. Am J Ophthalmol 139: 350-351.

Wallon M, Kodjikian L, Binquet C, Garweg J, Fleury J, Quantin C, Peyron F 2004. Long-term ocular prognosis in 327 children with congenital toxoplasmosis. Pediatrics 113: 1567-1572. 